\title{
Analysis of the Twin Relationship between "Visual Schema Language" and Painting Art
}

\author{
Li Songlin
}

School of Arts and Design, Hubei Engineering University

\section{Keywords: Applied; Painting Art; Visual Schema Language}

\begin{abstract}
In this paper, the development and current situation of "painting art" and "visual schema language" are briefly described with time as the clues, and comparisons are made from a variety of perspectives. The results show that in spite of the close relationship, their ontological significance and development direction are different.

The visual schema language and the painting art are used as a metaphor "twin" in this study. It means that they are confusing but actually different, and they have different specific directivity, application functionality, and derivative scope. Clarification of the relationship will help develop the related disciplinary systems and even construct a new disciplinary system. This paper elaborates on the following three aspects.
\end{abstract}

\section{Explanation of "Painting Art"}

Since the $20^{\text {th }}$ century, art forms have coexisted in multiple ways. After the existing art forms and various concepts, materials, technologies and other elements have been continuously merged and collided, new art theories and forms have been derived such as performance arts, science and technology arts, digital arts, installation arts, concept arts. "Art" was once defined by others, yet it is now difficult to define "art", because the art that is happening or is about to happen often goes beyond the scope of the previous scope of definition.

With the development of the times, the concept of art is constantly being broken, and the boundaries of art have also been continuously expanded and broadened by artists. The development of "painting art" is synchronized with the development of artistic concepts, because "painting" is only one of many forms of art. The birth of "painting art" dates back to hieroglyphs. The separation of "schema and Chinese characters" makes painting a special art form. In the evolving historical process, the forms, materials and functions of painting art have also changed accordingly.

Different from the history of Chinese painting art, the ideological and cultural movement prevalent in Europe in the $14^{\text {th }}$ and $17^{\text {th }}$ centuries directly affected the development of painting art. Originally, the painting art replaced the old theology form with scientific visual analysis, and the painting art function went from serving religion to singing about human nature. In the $17^{\text {th }}$ and $18^{\text {th }}$ centuries, Galileo, Copernicus and other scientists' studies on the celestial bodies of the universe disrupted the theological system of genesis, and the geographical discovery driven by new route made art and science together became an important way of thinking and civilization, triggering the generation of the post-impressionism, Cubism, Expressionism, Dadaism, Fauvism in the context of the Second Industrial Revolution.

In the middle of the $20^{\text {th }}$ century, the "art" form was not only reflected in the combination with science and technology but also in the combination with philosophy. For example, the emergence of "conceptual art" led to a great transformation or even a qualitative change in the traditional concept of painting art.

In the early $21^{\text {st }}$ century, information technology was highly developed, and the Chinese and Western cultures were deeply integrated. The concept of pluralism in the "painting art" is unprecedented. Some scholars believed that Chinese painting was a dead end, whereas others insisted that thoughts and concepts were weapons to defend the existence of painting. The author believes that under the combined forces of artistic concepts, science and technology, philosophy, history and other disciplines, the contemporary and future "painting art" can generate a variety of 
answers that meet the needs of the times by continuously questioning "itself".

\section{Explanation of "Visual Schema Language"}

\section{Analysis on Historical Background of the Concept "Visual Schema Language"}

Analysis of the Background of Discipline Construction: Over the past 10 years, there are serious differences between colleges and universities in China on the professional basics orientation of art and design. Many colleges and universities are lagging behind in the development of related disciplines, and they are obviously under the passive traction of the "eight major academy of fine arts"; in 2016, the Ministry of Education designated a list of specific applied colleges and universities, which meant that relevant colleges universities would need to position themselves appropriately.

The concept of "visual schema language" is not only based on the above historical background but also originated from the development of art and design education. For example, the history of Chinese art before the 20th century could be regarded as the traditional visual schema language contents with Chinese characteristics; the history of art and design in the $20^{\text {th }}$ century might be regarded as the development of modern visual schema language concepts. For another example, Liu Haisu, Lin Fengmian, Xu Beihong and other educators who returned from France in the 1920s took the lead in opening the curtain of modern art education; the art form and the contents enriched the traditional visual schema language. In the 1950s and 1960s, due to the political influence, the visual language expression styles and teaching ideas were largely originated from the Suzhou-style teaching system. In the 1970s, with resumption of college entrance examination, the construction of college and university discipline was started from the real sense. Its visual language performance style and teaching philosophy still drew lessons from the Suzhou-style teaching system. In the 1980 s, the introduction of the Western "constitution and expression" system enriched the domestic existing disciplinary system, but its influence was limited to the design-related majors. From the 1990 s to the present, the number of design majors has increased, and the concept of "design" courses that are more creative, flexible and targeted have emerged as the times require. Besides, the comprehensive ability of interdisciplinary teachers has also increased, and the teaching concepts of art and design have begun to melt into each other. All these factors further promote the development of education concept of modern art and design in China. At the beginning of the $21^{\text {st }}$ century, with the representative of the China Academy of Art, the domestic representative art universities set up specialized basic course departments to solve the basic modeling problems of visual arts. Its teaching purpose can be regarded as cultivating the basic abilities of "visual schema language".

Based on the above clue analysis, it can be concluded that "visual schema language" is different from "painting art" and its scope and significance are broader.

\section{Explanation of the Concept of "Visual Schema Language"}

The said word "visual language" comes from British Design Basic Series - Visual Language (David Cohen, 2006). From the book, it is understood its teaching concept based on visual language. After further exploring the formation of its concept, it is found that in the middle of the $20^{\text {th }}$ century, the high combination of Western art and science is a combination of psychology and art phenomena on a strict experimental basis, so as to further analyze the relationship between art form and visual perception, and scientifically demonstrate the power of visual function. This research result has laid a scientific foundation for modern visual art theory.

The term "visual schema" comes from Visual Schema (Cao Fang et al., professors of Nanjing University of the Arts, 2008). This book analyzes and explains in detail the different styles of the "schema" of visual expressions from the perspective of "language" or "grammar".

The term "schema language" stems from Study on the Basic Education of Modeling under the Logic of the Meta-narrative - Discussion on the Evolution of the Concept of Basic Teaching in Hubei Institute of Fine Arts (Cao Dan, July 2017) in the Ultravision \& Re-Foundation Re-exploration of Advanced Art Basics - Collected Papers for Visual Arts Educational International Forum in Hubei Institute of Fine Arts, in which "schema language" is mentioned as one of its basic courses 
According to the above theoretical basis, the author proposes the concept of "visual schema language". In other words, based on the positioning of "local, teaching, and applied" school running in colleges and universities and combined with the concepts of applied linguistics, basic skills in traditional painting art, performance experiments of materials, and common characteristics of music, literature, and other art forms, this paper builds its theoretical framework from "semantics, morphology, color, linguistics and grammar" and other elements, and envisages further study of the corresponding "visual schema language" curriculum system and even the "visual schema language system", so as to achieve the actual application functions and values of cultivating talents with "thick foundation, wide caliber, focusing on application and strong ability" in applied colleges and universities.

\section{Relationship between "Painting Art" and "Visual Schema Language"}

\section{They have different emergence time and varied application functions}

From the beginning of human birth, visual schema has the function of language. For example, the original graphics are the expression of man's meaning. Compared to the art form of painting art, it was discovered and used earlier. However, "painting art" comes first from the perspective of academic concepts.

The main application functions of "visual schema language" correspond to the characteristics of the visual profession. It has the basis of general "visual schema" knowledge in the field of visual arts, hence promising prospects. Its specific application involves all aspects of life; the application function of "painting art" corresponds to the human's spiritual world, such as aesthetic education function, pure artistic creation direction and corresponding skills, and its application scope is constrained to exhibition halls, galleries, family and other special space fields.

Therefore, "application" is the main function of visual schema language, and its application is reflected in all aspects of life. In contrast, aesthetic education is the main function of "painting art", and its application focuses on the spiritual field.

(II) Both have similar appearances but different intentions

The performance of both methods can also be said that skills training methods are mainly "schematic", and basic ability judgments are made on the basis of "accuracy". However, if they have different intentions, there should be different choices in skills training.

"Visual schema language" has a broad scope of application, which requires solid and comprehensive professional basic abilities. "Accuracy, vividness and creativity" can be used as the basic evaluation criteria. Among them, "accuracy" includes humanistic speculations such as meaning clarification, setting, creativity and expressiveness; "vividness" indicates that visual schema should be full of rhythm, which means understanding and mastering the order of schema language; "creativity" is the creative way of thinking and materials experiments.

To master a language, the author needs to understand its basic elements, accumulate rich related vocabularies, learn various language expression skills, and analyze the performance of various language carrier materials. Ultimately, the author needs to translate all elements into appropriate words to express the language content, meaning that the "visual schema language" must be closely related with humanities, skills, materials, arts and other factors. For example, the elements in the visual schema language correspond to notes in music, words in literature, whereas the beauty of visual forms correspond to fluctuating scenes in literature and rhythms in music. Therefore, in the meantime of training students' abilities, the talents with 'thick foundation, wide caliber, focusing on application and strong ability" are cultivated.

As a special form of art, "painting art" has been using its visual schema language for thousands of years to achieve its intentions. For example, people with simple intentions may clarify himself/herself only with one pen and one piece of paper; people with the intention of "traditional painting art" should understand the historical background and skills of traditional art; people with "conceptual painting art" may only have a clear understanding after understanding the concept of traditional and modern paintings, and then embark on the concept of painting art road based on this understanding and with the help of visual schema language! 
It is difficult to define the evaluation criteria for "painting art", because each person has distinct "intentions". The evaluation criteria are often based on a certain point in the history, so they are not repeated here. In summary, the visual schema language affects the painting art. In turn, the painting art also promotes the development of the visual schema language.

For the "visual schema language", as long as the human visual sense still works, it has the value of inevitable existence. In the future, linguistic elements such as vocabulary, grammar, and carrier materials will be more abundant, and audio-visual touch synthesis language will be more cross-cutting, such as today's voice video and audio technology.

Conclusion: "Painting art" and "visual schema language" are brothers, and they will definitely affect each other in the future. In the paper, the concept of "visual schema language" is proposed on the basis of the research of relevant experts. The author's intention is to make contribution to the establishment of related systems in the applied colleges and universities. However, due to limited capabilities, there are still many areas that have been uncovered and need to be further clarified and improved.

\section{Acknowledgement}

[Foundation]: 2018 University Teaching Research Project: Research on the Construction and Application of "visual schema language" Curriculum System (No.: 2018020)

\section{References}

[1] Liu Maoping \& Yin Xiaobin. Ultravision \& Re-Foundation - Re-exploration of Advanced Art Basics - Collected Papers for Visual Arts Educational International Forum in Hubei Institute of Fine Arts [C]. Wuhan: Hubei Fine Arts Publishing House, 2017.

[2] David Cohn \& Scott Anderson. British Design Basic Series - Visual Language [M]. Shanghai: Shanghai People's Fine Arts Publishing House, 2012.

[3] Shizhao N, Zheng W, Wangmo P, Yuan N, Peng L. Big Data Prediction of Durations for Online Collective Actions based on Peak's Timing [J]. Physica A: Statistical Mechanics and its Applications, 2018, 55: 130-139. 